\title{
ELECTRONIC MAGNETIC RELAXATION IN MANCANESE FERRITES
}

V.A.M. Brabers and A.A. Scheerder, Department of Physics,

Eindhoven University of Technology,

P.0. Box $513,5600 \mathrm{MB}$ Eindhoven, The Netherlands

\section{Abstract}

Two electronic magnetic relaxation phenomena are reported for the manganese ferrite system, which are both explained by electron hopping processes between octahedral iron ions: the first one by hopping between $\mathrm{Fe}^{2+}$ and $\mathrm{Fe}^{3+}$ ions with a $\mathrm{Mn}^{2+}$-ion as nearest neighbour and the second one by hopping between iron ions with only iron nearest neighbours.

\section{Introduction}

It has been well established that in highpermeability spinel ferrites, the dispersion of the dynamic magnetic permeability and the maxima in the loss factor are caused by electron diffusion between cations present in different valency states like e.g. the $\mathrm{Fe}^{2+}$ and $\mathrm{Fe}^{3+}$-ions ${ }^{1,2)}$. However, in the manganese ferrite system, $\mathrm{Mn}_{\mathrm{x}} \mathrm{Fe}_{3-\mathrm{x}} \mathrm{O}_{4}$, two distinct electronic relaxation phenomena are observed around the composition $x=0.8$, with activation energies of 0.015 and $0.06 \mathrm{eV}$, respectively 3 ). The assignment of these two relaxations to elementary processes is still controversial: inter- and intra-atomic electron transitions between the $\mathrm{Fe}$-ions are claimed as one interpretation. whereas electron transitions between iron ions and/or manganese ions are another ${ }^{4}$ ). In the present paper, the composition dependence of the electronic magnetic relaxations in the manganese ferrite system is reported and compared with the analogue $Z_{n}$ ferrite system, from which indications about the origin of the two relaxation processes in the Mn-system are obtained.

\section{Experimental}

Polycrystalline manganese and zinc ferrous ferrites toroids with inner and outer diameters of 30 and $35 \mathrm{~mm}$, respectively, were prepared by ceramic techniques. Special precautions were taken to obtain single phase spinel materials ${ }^{5-7}$ ). The complex initial permeability was measured by means of a LCR resonance method, using coils wired on the ferrite toroids, in the temperature range of $4-300 \mathrm{~K}$ and frequency range of $20-500 \mathrm{kc} / \mathrm{sec}$. For all the measurements the maximum value of the magnetic induction used in the experiments was $5 \cdot 10^{-5} \mathrm{~T}$, independent of the frequency.

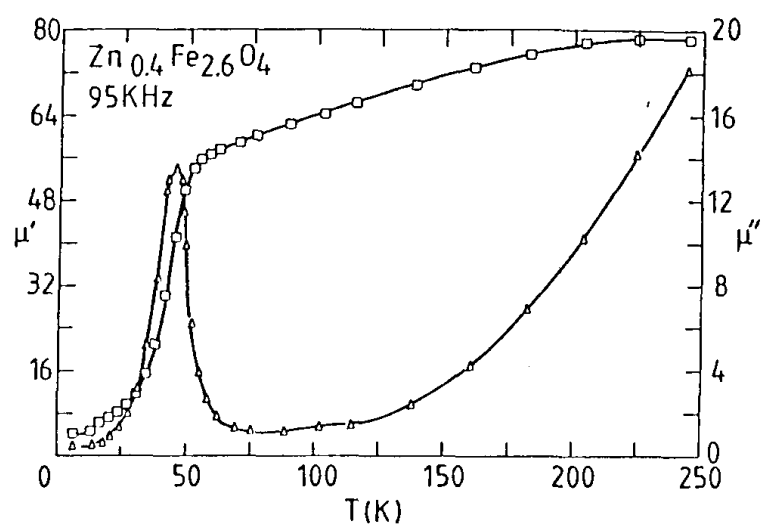

Fig. 1 The complex permeability $\mu=\mu^{\circ}-j \mu^{\prime \prime}$ for $\mathrm{Zn}_{0.4} \mathrm{Fe}_{2.6} \mathrm{O}_{4}$ at $95 \mathrm{kc} / \mathrm{s}$ as a function of temperature.
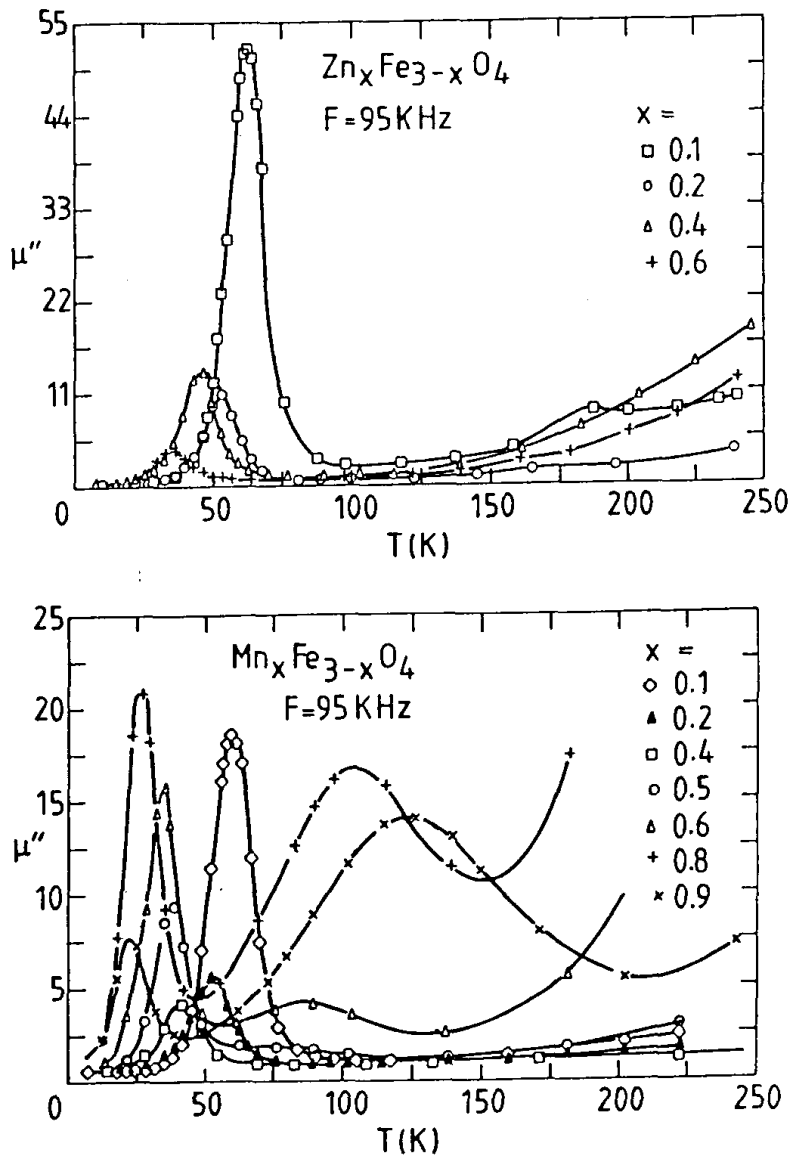

Fig. 2a and $b$ $\mu^{\prime \prime}$ as function of temperature for the Mn and $\mathrm{Zn}$ ferrite system with the additional parameter $x$, the zinc or manganese concentration.

Results and Discussion

For all the manganese as well as for the $\mathrm{Zn}$ ferrite materials. clear exponential magnetic relaxation effects are found in the complex permeability $\left(\mu^{\prime}-j \mu^{\prime \prime}\right)$. A typical example is shown in fig. 1. where the temperature dependence of $\mu^{\prime}$ and $\mu^{\prime \prime}$ is plotted for $\mathrm{Zn}_{0}{ }_{4} \mathrm{Fe}_{2}{ }_{6} \mathrm{O}_{4}$ at $95 \mathrm{kc} / \mathrm{s}$. From the exponential shift of the maxima in $\mu^{\prime \prime}$ with frequency, activation energies are determined as functions of the compositon of the ferrite.

In fig. $2 a$ and $2 b$, the imaginary part $\mu^{\prime \prime}$ is plotted as a function of temperature with the manganese and $z$ inc content $X$ as a parameter. In the zinc ferrite system only one electronic relaxation phenomenon is observed, as can be seen from the single peak in the $\mu^{\prime \prime}-T$ curve. In the manganese system, however. two relaxation phenomena $A$ and $B$ are observed 


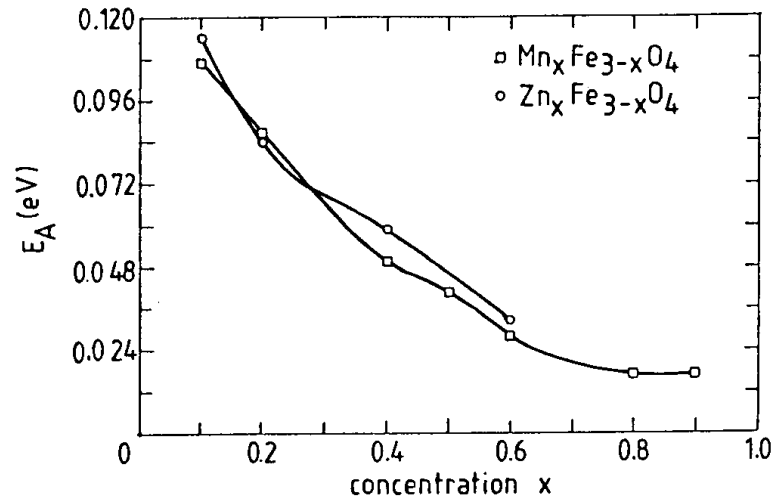

Fig. 3 The activation energy of the electronic relaxation in the zinc ferrite system compared with the activation energy of process $A$ in the manganese ferrite system.

for the compositons between $0.6 \leq x \leq 0.9$, and only one for compositions with a lower manganese content $x$ $\leq 0.5$. In fig. 3 the activation energy of the magnetic relaxation effect in the zinc ferrite system is compared with the energy determined from the manganese system; for the manganese composition between $x=0.6$ and $x=0.9$, the values for the low temperature effect $A$ has been plotted. From the nearly identical values of the energies for the manganese and $z$ inc concentration below $\mathrm{x}=0.6$ and the rather small and gradual changes in $E_{A}$ with increasing Mn-concentration, the conclusion seems to be obvious, that the electronic relaxation phenomenon observed in the zinc ferrite system and the phenomenon $A$ in the Mn-system are due to the same mechanism, i.e. a ions on the octahedral sublattice of the spinel structure. This conclusion is further supported by the fact that the $\mathrm{Zn}^{2+}$-ions are located on the tetrahedral sublattice of the spinel structure, which results in a concentration of $(1-x) \mathrm{Fe}^{2+}$ ions on the octahedral sites; In the manganese ferrous ferrites, the $\mathrm{Mn}^{2+}$-ions have also a tendency to be located on the tetrahedral sites ${ }^{8}$. Which results in a nearly identical ionic configuration for the octahedral sublattice in both systems: $(1-\mathrm{x}) \mathrm{Fe}^{2+}$ ions and $(1+x) \mathrm{Fe}^{3+}$ ions.

Electrical conductivity measurements we performed on single crystals showed further that the composition dependence of activation energy for the conductivity behaves in a similar way as the magnetic activation energy, which is a strong evidence for the proposed $\mathrm{Fe}^{2+}-\mathrm{Fe}^{3+}$ electron exchange mechanism. An additional evidence for the same origin of the
$\mathrm{Fe}^{2+}-\mathrm{Fe}^{3+}$ relaxation in the zinc ferrite system and the mechanism $A$ in the manganese system is the equal pre-exponential factor $\tau_{0}$ describing the exponential relaxation in both systems: $T_{0}=T \exp -E / k T$; with $T_{0}$ varying between $10^{-12}-10^{-9} \mathrm{~s}$ depending on $\mathrm{X}^{\mathrm{W}}\left(\mathrm{Mn}^{2+}\right.$ or $\mathrm{Zn}^{2+}$ concentration)

Now. it seems apparantly to attribute the mechanism $B$ in the manganese system to the occurrence of an increasing number of octahedral $\mathrm{Mn}^{2+}$, as it is known that for $x=1.0$ up to $20 \%$ of the manganese ions can be located on the octahedral lattice, depending on the thermal treatment of the specimens ${ }^{8}$ ). In order to study this in more detail, we performed permeability measurements on a specimen $\mathrm{MnO}_{0} \mathrm{Fe}_{2} \mathrm{~F}_{2} \mathrm{O}_{4}$ after different thermal treatments to change the octahedral Mn-concentration. As the absolute value of $\mu$ " can also depend on the value of $\mu^{\prime}$. due to the microstructure of the specimens, the loss tangent $\delta=\mu^{\prime \prime} / \mu^{\prime}$ is now plotted in fig. 4. The phenomenon A turns out to be independent of the thermal treatment, whereas the strength of relaxation $B$ is strongly influenced by the annealing treatment i.e. by t the octahedral Mn-concentration. The relaxation $B$ can not be Mn-concentration. The relaxation between $\mathrm{Mn}^{2+}$ and $\mathrm{Mn}^{3+}$ or $\mathrm{Fe}^{3+}$ ions, because the energy needed for such a transition exceeds $0.3 \mathrm{eV} 9$ ), whereas for the process $B$ we found values of $E$ between 0.060 and $0.075 \mathrm{eV}$. However, the annealing experiments show clearly that the concentration of the octahedral manganese ions affects the relaxation $B$ !

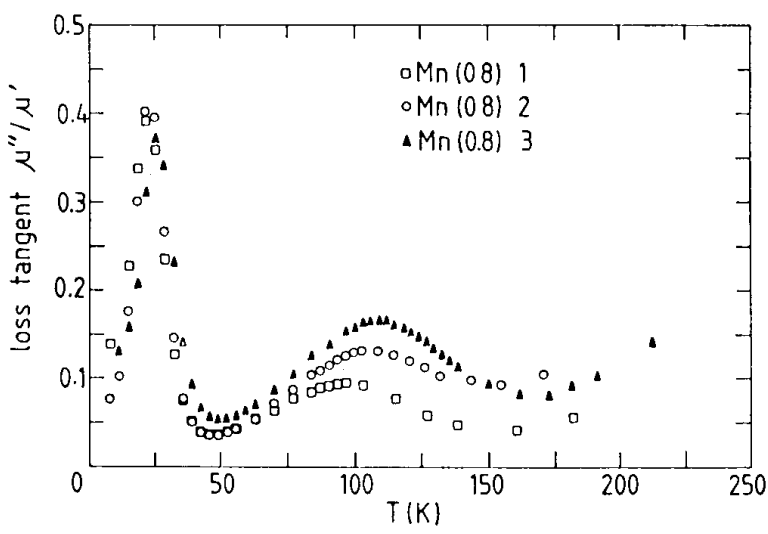

Fig. 4 Temperature dependence of the loss tangent $\mu^{\prime \prime} / \mu^{\prime}$ of $\mathrm{Mn}_{0.8} \mathrm{Fe}_{2.2} \mathrm{O}_{4}$ measured on specimens after different heat treatment.

1. As prepared and cooled from $1300^{\circ} \mathrm{C}$ to room temperature in 2 hours.

2. Annealed at $800^{\circ} \mathrm{C}$ in sealed silica tube, and cooled within 30 minutes to room temperature.

3. As 2 but quenched to room temperature.

The peak in the $\mu^{\prime \prime}-T$ curve for the relaxation A in the Mn-system can be fitted by one single exponential relaxation, which means that there does not exist a distribution of relaxation times for this mechanism. The same sharp relaxation was observed for the Zn-system but a similar investigation of the relaxation in e.g. nickel ferrous ferrites showed substantial broadening of the $\mu^{\prime \prime}-\mathrm{T}$ peak indicating a distribution in relaxation times for the Ni-ferrous ferrite system ${ }^{10}$ ). The different behaviour of the $\mathrm{Zn}$ and $M n$ ferrites on one side and of the nickel ferrite system on the other can be related to the inverse structure of the nickel ferrites. The $\mathrm{Ni}^{2+}$ ions are located on the octahedral sites, by which the electronic energy levels of the iron- nearest neighbours will be influenced by the deviating charge of the $\mathrm{Ni}^{2+}$ ion. In fact, one expects the activation energy for the electron transfer between the iron ions to depend on the number of $\mathrm{Ni}^{2+}$ nearest neighbours. and since the $\mathrm{Ni}^{2+}$ and iron ions will be statistically distributed on the octahedral sites, a distribution in relaxation times is expected. In the zinc ferrites only electronic and no static ionic disorder on the octahedral sites is possible, closely related to the $\mathrm{Fe}^{2+}$ and $\mathrm{Fe}^{3+}$ charge distribution and only one single relaxation time is expected for the electron hops between the adjacent iron ions. For the manganese ferrites we have more or less the same situation as for the zinc ferrites, with an exception for larger Mn concentrations between $x=0.5$ and 1.0 , where some $\mathrm{Mn}^{2+}$-ions are entering the octahedral sublattice. The 
most obvious explanation of the mechanism for relaxation $B$ is an electron transfer between $\mathrm{Fe}^{2+}$ and $\mathrm{Fe}^{3+}$-ions which are adjacent to an octahedral $\mathrm{Mn}^{2+}$-ion. Due to the bivalent manganese ion and the relative large diameter of the $\mathrm{Mn}^{2+}-\mathrm{ion}$, there must be a distinct effect upon the energy levels of the neighbouring iron ions, which results in a quite different relaxation time for an electron hop between $\mathrm{Fe}^{2+}$ and $\mathrm{Fe}^{3+}$-ions with òr without a manganese nearest neighbour.

For the composition $x=0.8$ about $5 \%$ of the octahedral sites are occupied by $\mathrm{Mn}^{2+}$ ions ${ }^{7)}$. which seems to be an optimum for the simultaneous appearence of relaxation $A$ and $B$. Both relaxations can be interpreted on the basis of electron hopping between $\mathrm{Fe}^{2+}$ and $\mathrm{Fe}^{3+}$ ions only, if we take a certain ionic disorder on octahedral sites into account: process $B$ is caused by electron hopping between iron ions with an octahedral $\mathrm{Mn}^{2+}$ ion as nearest neighbour and process $A$ is caused by the electron hopping between iron ions without $\mathrm{Mn}^{2+}$ as nearest neighbour. So we can conclude that in the manganese ferrite system the presence of octahedral $\mathrm{Mn}^{2+}$-ions introduces a static ionic disorder, which gives $r$ ise to the occurence of two detached electronic magnetic relaxations.

\section{References}

[1] J. Smit and H. Wijn, Ferrites, Eindhoven. Philips Publ. (1959).

[2] S. Krupicka, Physik der Ferrite, Braunschweig Vieweg. (1973)

[3] A. Broese van Groenou, Low frequency magnetic relaxations in manganese ferrous ferrites at low temperatures, J. Phys. Chem. Solids 28, 325 (1967).

[4] S. Krupicka and K. Zaveta, Magnetic-after effects in ferrimagnetic oxidic spinels, J. Appl. Phys. 39, 930 (1968)

[5] A.L. Stuyts, D. Veeneman, Preparation of ferrous zinc ferrites with high saturation magnetization, A. Broese van Groenou. Proc. First Int. Conf. Ferrites, University of Tokyo Press, 236 (1970).

[6] B. Cillot, R.M. Ben Loucif and A. Rousset. Electrical conductivity of zinc-iron ferrites in vacuum and in the presence of oxygen, Phys. Stat. Sol. 65, 205 (1981).

[7] V.A.M. Brabers, Thesis Eindhoven University of Technology (1970).

[8] V.A.M. Brabers, Cation migration, cation valencies and the cubic-tetragonal transition in manganese ferrites, J. Phys. Chem. Solids $\underline{32}$. 2181 (1971)

[9] V.A.M. Brabers and J.H. Hendriks, Electronic magnetic relaxation in manganese ferrites, Sol. State Comm. 6. 795 (1968).

[10] T.E. Whall. V.A.M. Brabers, to be published. 
LOW TEMPERATURE ELECTRICAL PROPERTIES OF MAGNETITE AND MI-FERRITES

Zden̋̌k Šimsa and Victor A.M. Brabers (1)

\author{
Institute of Physics, Czechoslovak Academy of Sciences, \\ 18040 Prague 8 , Czechoslovakia \\ (1) Department of Physics, Eindhoven University of Technology \\ 5600 MB Eindhoven, The Netherlands
}

Electrical resistivity and thermoelectrio power measurements have been made on single crystals of manganese ferrites, $\mathrm{Mn}_{\mathrm{x}} \mathrm{Fe}_{3}-4 \mathrm{O}_{4}$ $(x=0,0.5,0.7,0.8,0.9$ and 0.95$)$ in the temperature range $10 \mathrm{~K}$ to $300 \mathrm{~K}$. Below the Verwey transitjor ' $\mathrm{T}$ ' of magnetite, the thermoelectric power is strongly influenced by the oxygen nonstoichiometry of the samples whereas the resistivity exhibits hardly any dependence or the changes of the oxygen content. Starting from the lowest temperatures, the electrical properties are explained in terms of the impurity band, variable range hopping, small polaron band and small polaron hopping conduction mechanisms where the long rarige and the short-range orderings have to be taker into account.

\section{Introduction}

Extensive experimental and theoretical work have been done to understand the electronic structure and electrical transport mechanismsi in magnetite $\left(\mathrm{Fe}_{3} \mathrm{O}_{4}\right)$ and other spinel ferrites. Starting with early investi gations of Verwey $[1,2]$ who discovered a jump of two-orders of magnitude of the electrical resistivity $\rho$ of magnetite at $\mathrm{T}_{\mathrm{Y}} \approx 120 \mathrm{~K}$, a vast numbor of papers have been devoted to studying of this first-order structural, magnetic and electrical phase transition (see e.g. $[2-8])$.

Ir the same time, work on the electrical properties of the "substituted magnetites", i.e. iron-excess mixed ferrites like cobalt ferrites [9], manganeso ferxites [10,11], nickel ferrites [12] etc. was going on, revealing that the classical semiconductor one-electron band picture breaks down. A new concept of more or less localized charge carriers (small polarons) was developcd to account for the observed electrical, magnetis and optical properties of monoxides, sesquioxidus and more complex magnetic oxidio materials (tor reviews see e.g. [13-15]). 'lakjng into asogunt a splitting of the conduction levels, it was possible to explain a complex hehaviour of the thernoelectric power $\alpha$ near $\mathrm{T}_{\mathrm{y}}$ in the case of magnetite $[16,17]$.

Howsver, thes observed dependences of electrical properties of ferrites at low temporalides revealed early on that the simple small polaron picture must be modified in at least twis ways:

a) impurities present in ferritos

introduce band conduction or hopping of charee carriers which becomes important at $10 \mathrm{w}$ temporatures;

b) correlation effects must be introduced into thr simall polaron theories.

In sach a way, the behaviour of the eleotrical condurtivity and themsower of tho fluorine subritiated matretite [18] and the low temperatipe properties of nickel ferriteo [19] were described. Considering the correlation effects of small polarons (leadirg to short range ordering) Ihle and Lorenz [20] were able to explain the conductivity maximum occurring in magnetite at about $300 \mathrm{~K}$.

In this report, a more detailed investigation of the electrical resistivity and thermoelectric power. of several samples of magnetite is made in order to clarify the behaviour of $a$ below $T_{\mathrm{y}}$. Measurements of electrical properties of iron-rich manganese ferrites give further informations on the influence of substitutional disorder on the behaviour of charge carriers.

\section{Experimental Eart}

Samples.

Single crystals of magnetite and manganese ferrites in the systein $\mathrm{Mn}_{x} \mathrm{Fe}_{3} \mathrm{O}_{4}$ were prepared by the travelling - molten zone technique as described elsewhere [21]. After growth the single crystal rods (approx. 5mm in diameter) were additionally heat-treated at $\mathrm{T}_{\mathrm{h}}=1470 \mathrm{~K}$ for 70 hours and slowly cooled to room temperature in controlled atmospheres, to secure the adjusted oxygen stoichiometry. From the rods, rectangular samples of $1 \times 5 \times 12 \mathrm{~mm}^{3}$ were cut and finely polished. The remaining parts of the crystals were used for chemical analysis to determine final contents of cations and the active oxygen. Results of the analysis, partial oxygen pressures during heat-treatment and crystal axes are listed in Table 1. It was found that the Eradients in chemical compositions along or across the samples were within the error limits of chemical analysis (i.e. 0.02 and 0.002 for $x$ and $\gamma$ resp.). Electrical contacts were mado by rubbing in an eutectic In-Ga alloy at the opposite faces of the samples.

\section{Electrical registivity.}

A four point de potentiometric method was used to determine the electrical resistivity

Table 1

Final compositions and treatment conditions of $\mathrm{Mr}_{1} \mathrm{Fe}_{3}-x^{\mathrm{O}} 4+\gamma$

\begin{tabular}{|c|c|c|c|c|c|}
\hline mple & $x$ & $\gamma$ & $\log \mathrm{pO}_{2}$ & $\mathrm{~T}_{\mathrm{h}_{1}}(\mathrm{~K})$ & $\operatorname{axis}$ \\
\hline${ }^{M}$ & 0 & 0.046 & -6.0 & 1370 & $(110)$ \\
\hline B & 0 & 0.00 & 7.6 & 14 & $<1$ \\
\hline c & 0 & $0.00^{\circ}$ & $-8,3$ & 14 & 6 \\
\hline D & 0 & 0.006 & -8.5 & 14 & $\langle 110\rangle$ \\
\hline$E$ & 0 & 0.00 & -8.8 & 14 & $\langle 110\rangle$ \\
\hline $\mathrm{F}$ & 0 & 0.00 & -7.6 & 14 & $\langle 110\rangle$ \\
\hline G & 0 & 0.004 & -10.2 & 1470 & $\leqslant 110\rangle$ \\
\hline 0.5 & 0.52 & 0.009 & -6 & & \\
\hline 0.7 & 0.70 & 0.009 & -6 & 1470 & $<14$ \\
\hline 0.8 & 0.79 & 0.0 & -6 & 1470 & \\
\hline 0.9 & 0.90 & 0.00 & 6 & 1470 & \\
\hline 0.91 & 01.96 & 0.002 & 6 & 1470 & $\therefore 11$ \\
\hline
\end{tabular}

0018-9464/88/0300-1910\$01.00@1988 IEEE 
of the low resistive samples at variour current dersities. Fosistances (accuracy better than $1 \%$ w we determined al such current values where okm's law was fulfil]ed. At low tempexatures wher resistances reached $10^{6} \Omega$ a voltage drop at probes was deternined using a Keithley 640 electroneter with the in put resistance exceeding $10^{15} \Omega$. At very hieh resistances $(>1011 \Omega)$ a two point method exploiting a feed back loop of the electrometer was used.

Sample temperature was varied by means of a liquid helium continuous-flow cryostat; temperature control (with accuracy of $0.1 \mathrm{~K}$ ) was achieved with a DTC 2 (Oxford instruments) controller connected to a C.L.T.S. sensor.

\section{Thermolectrio power.}

To determine the thermoclectric power per $1 \mathrm{~K}$ (Scebeck coefficient $\alpha$ ) the opposite enda of the sample were clamped in the arms of the aluminized sample holder (enabling a good thermal contact and securing a high electrical isolation of sample from the holder). The arms could be individually heated to establish a temperature gradients up to $5 \mathrm{~K} / \mathrm{cm}$ along the sample in both directions. Temperatures of arms were measured by $A 11+0.03 \%$ Fe vs.chrome] thermocouples and the thermopowers generated by temperature gradients were deternined by oper input Keithley 640 electrometer. Slopes of the thermopower va. temperature differences plots were used to calculate the values of $a$.

\section{Results}

Magnetites

Temperature dependences of the electrical vesistivitios of magnetite samples in $\log \rho$ vs. $1 / \mathrm{l}$ representation are shown in Figs. 1,2 .

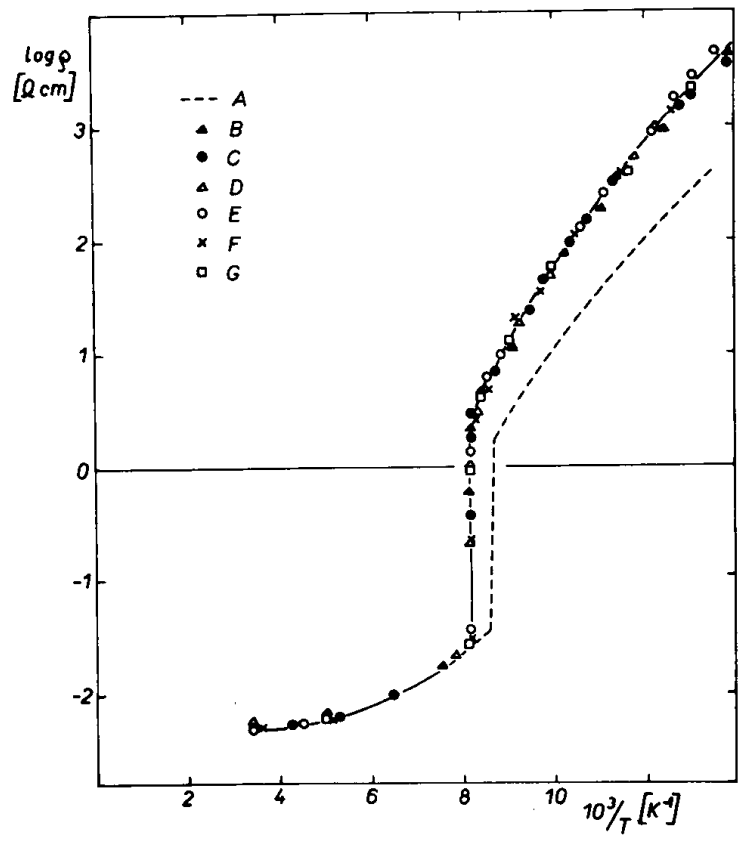

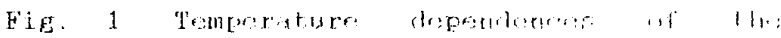
resiativity of magnetites in the $80 \mathrm{~K}$ is, 300

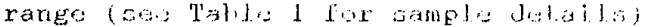

It is seen that with the exception of the highly non stoichionetric sample A all other specimens have identical temperature dependences of resistivity down to $10 \mathrm{~K}$. Although the concept of activation cnergy has different meanings in various theories of transport mechanisms it is worthwhile (for the sake of comparison and estimation) to define a conductivity activation energy as

$$
\varepsilon(\mathrm{eV})=1.895 * 10^{-4} \mathrm{~d}(\log \rho) / \mathrm{d}(1 / \mathrm{T})
$$

Values of $E$ as determined for the magnetite samples just above and just below the Verwey transition and at $10 \mathrm{~K}$ are listed in Table 2 .

Table 2

Activation energies for magnetites (see Table 1 for sample details)

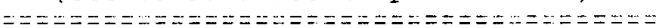
Sample $\in(\mathrm{T}>\mathrm{TV}) \quad \epsilon(\mathrm{T}<\mathrm{TV}) \quad \epsilon(\mathrm{T}=10 \mathrm{~K})$

$\begin{array}{llll}\text { A } & 0.05 & 0.12 & 0.006 \\ B \text { to } G & 0.05 & 0.15 & 0.008\end{array}$

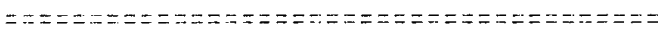

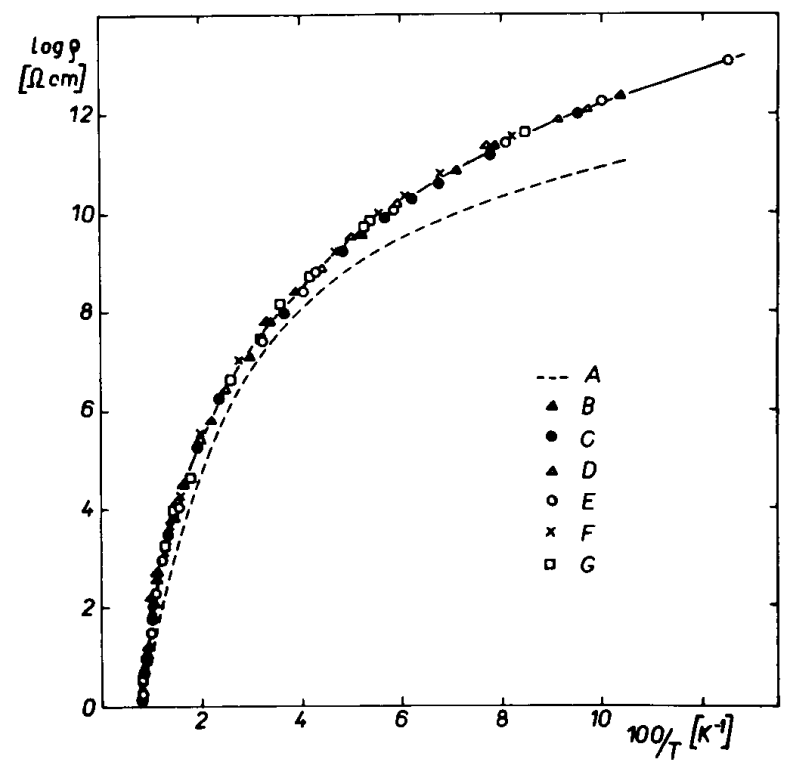

Fie. 2. Temperature dependences of the resistivities of magnetites at $10 \mathrm{~K}$ to $100 \mathrm{~K}$ (seo Table 1 for sample details).

The temperature dependences of the thermoelectric power for representative samples of magnetite are depicted in Fig. 3 . The other samples display intermediate behaviour and, to avoid possible confusion, were not included in Fig.3. A salient feature is the strong dependence of a below $T_{Y}$ wn the heat treatment conditions of samples, as upposed to the small changes of a above 'T' with a remaining practically constant up to room temperature. The most remarkable is the behaviour of sample $G$ where a transition trom n-type to p type conductivity occurs at $100 \mathrm{~K}$ followed by a maximum at $80 \mathrm{~K}$ and another transilion to notype at about $50 \mathrm{~K}$. bisow to $K$ ill samples behave in a similar medius $x$ with $x \rightarrow 0$ for $\mathrm{T} \rightarrow 0$. 
Talle 3

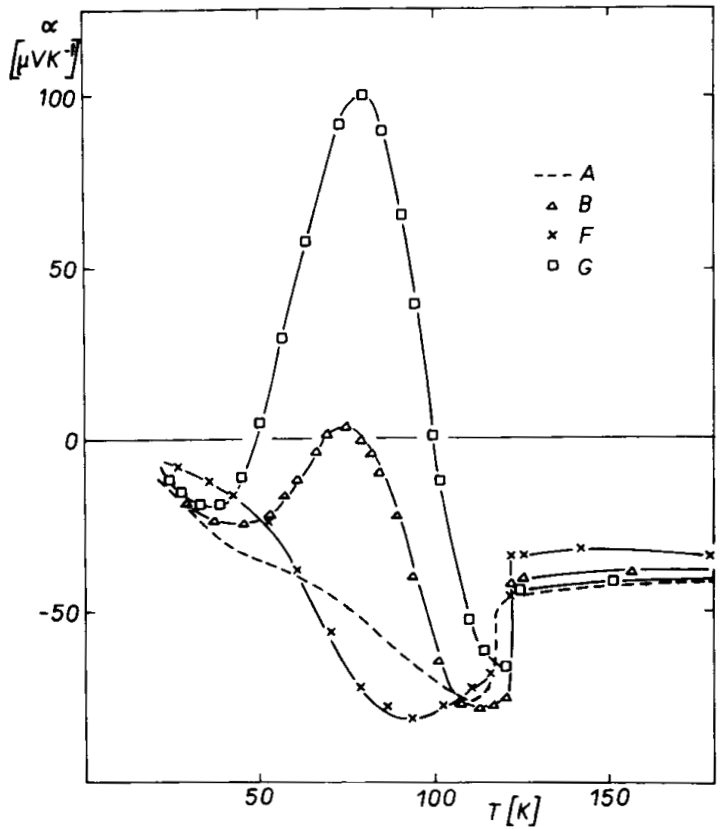

Fig. 3. Temperature dependences of the seebeck coefficient a for magretite samples.

Mn ferrites.

Temperature dependerces of the electrical resistivities of manganese ferrites are shown in Figs. 4 ard 5. At higher tenperatures (Fig.4), resistivities inorease with risine manearese content while the activation enorgies $\epsilon$, decreas attainine the mirinum value for $x=0.9$ - see table 3. Below $100 \mathrm{k}$ (Fie.5) the sequence of reastivities is altered, resulting in a roversed succession of $\rho$ with $x$. The only execption is $x=0.9$ ! sample for which $\rho$ and $\epsilon$ are larger than the values of the other samplos down to $15 \mathrm{~K}$.

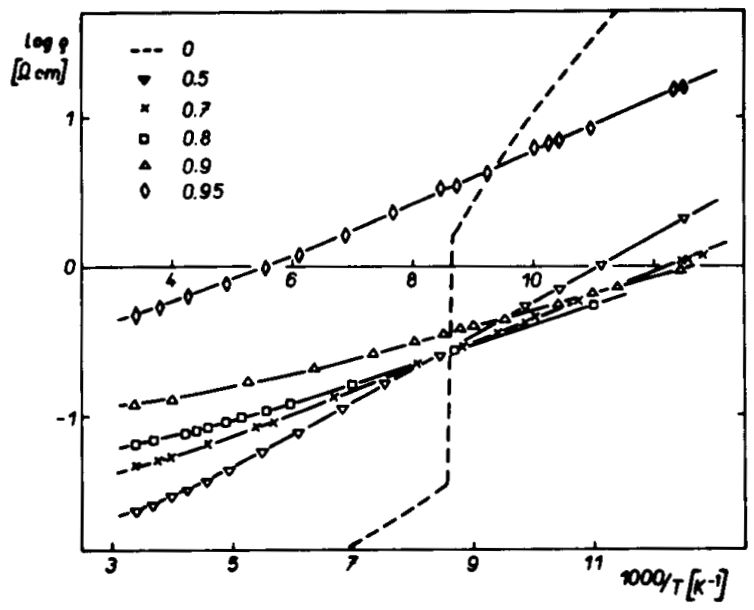

Fig. 4. 'Jemporature dependenese of thr eleotrival resistivitier of Mr forritus at sot $\mathrm{K}$ to $300 \mathrm{~K}$ ranes The symlws indimat. the

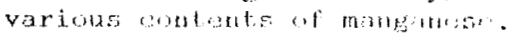

Aotivation energies for Mu-ferritos

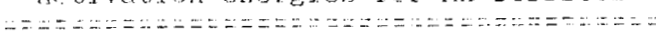
Samp $\mathrm{Le} \quad E(\mathrm{~T}=100 \mathrm{~K}) \in(\mathrm{T}=10 \mathrm{~K})$

$\begin{array}{lll}0.5 & 0.044 & 0.009 \\ 0.7 & 0.034 & 0.008 \\ 0.8 & 0.030 & 0.007 \\ 0.9 & 0.025 & 0.005 \\ 0.95 & 0.036 & 0.008\end{array}$

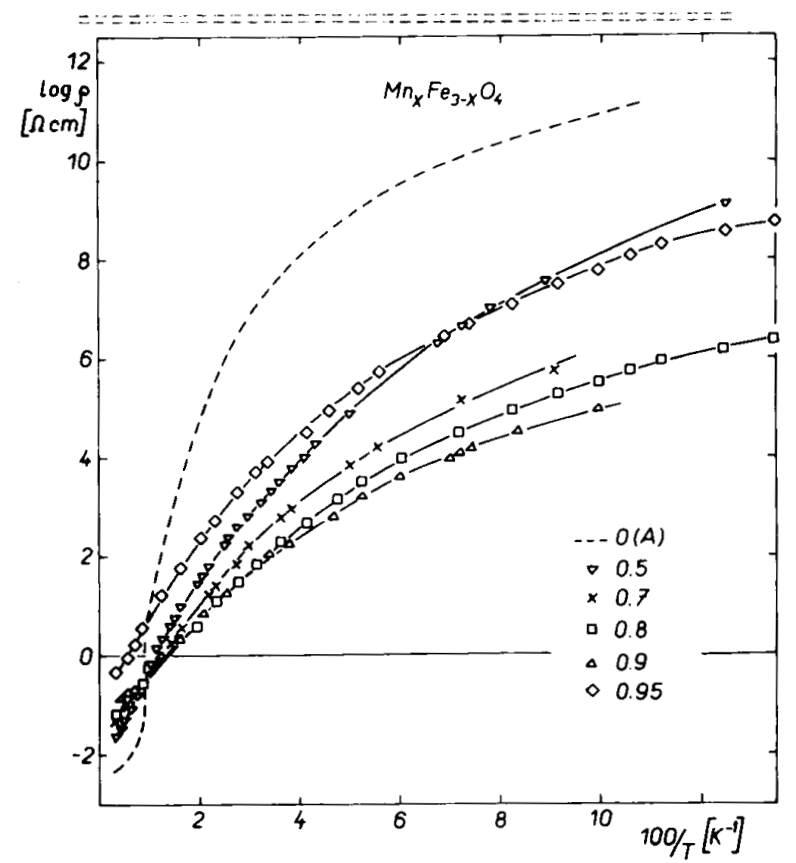

Fig. 6. Temperatire deperdences of the electrical resistivities of Mn ferrites in 10 $\mathrm{K}$ to $100 \mathrm{~K}$ region. The symbols indicale the various cortents of maneanese.

In Fig. 6 temperature dependenoes of the Seebeck coeficients of Mr-ferrites arc roprosented. Starting at room temperature a slight increase of $\alpha$ in decreasine temperatures is first observed. In the $150 \mathrm{~K}$ to $50 \mathrm{~K}$ region a reaches a maximum followed by a regular decroase (down tis zero) when $\mathrm{T}$ - : 0 .

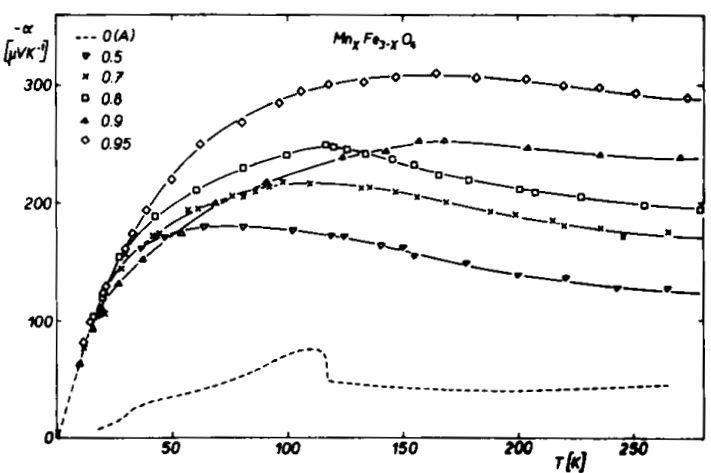

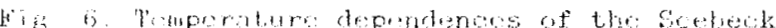

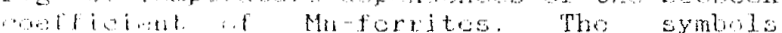
indionte the various contents of manganese. 


\section{Lisolsengror}

$\Lambda$ number of conduction mechanismo pres suggested to acoount for the comples bohaviuar of the temperature dopenderice of th. electrical resistivity of magnetite. Ln agrement with other experiments [22,23] our low temperatures measurements confirm the importarce of the impurity corduction mechanism. The impurities in tre form of cation vacancies are introduced in magnetite as a result of tho oxygen noustoichiometry (see Table 1) acting as donor centres. In manganese ferrites, the impurity levels are also formed by the electrons trapped at octahedral $\mathrm{Mn}^{3+}$ ion sites or in the neighbouring iron ions (for discussion of the trapping centers see $[10,11]$. The theory of correlated hopping transport leading to impurity band conduction [24] yields for the temperature dependence of resistivity the following formula

$$
\rho=\rho_{0} T^{-n}
$$

Relation (2) seems to be well fulfilled in our measurements as may be seen on $\mathrm{Fig} .7$ whink shows the linear depondence of logp vs. logl' at ' $\mathrm{I}<40 \mathrm{~K}$.

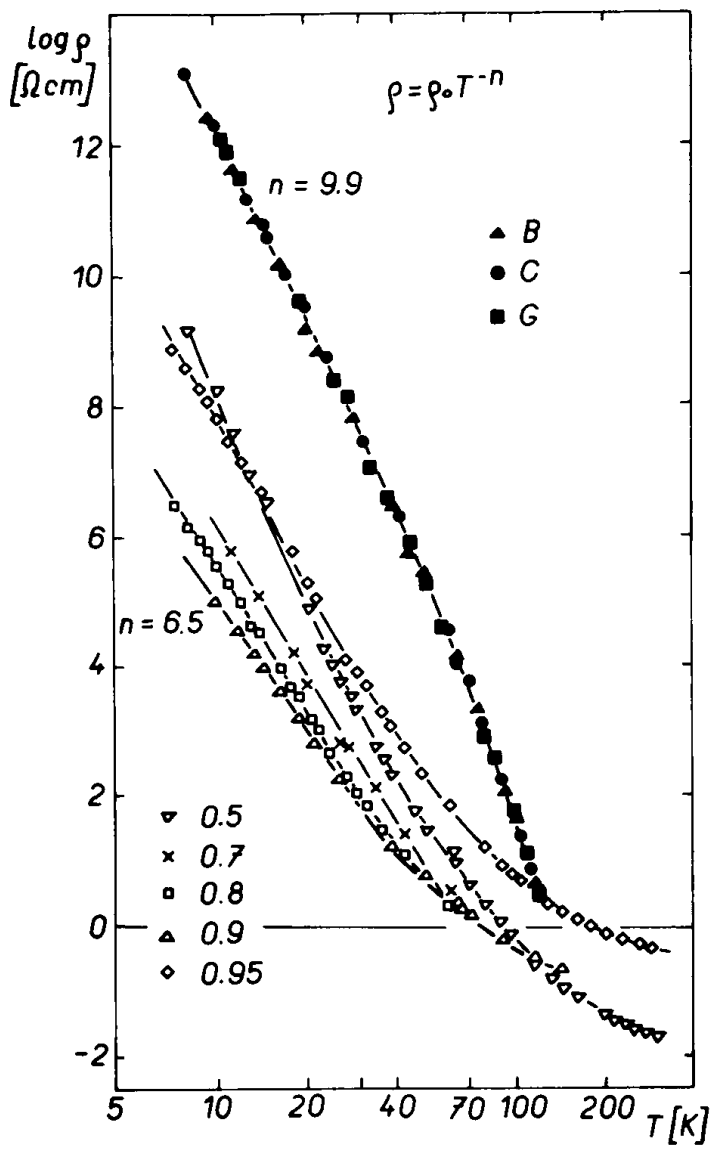

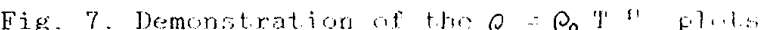

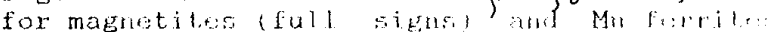

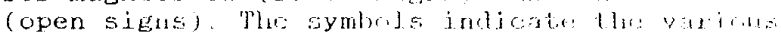
sample compositions.
Suct a relationship has abo beer find roontly in niobel ferrous ferrites [19]. Currelaled lopping is alog supporied by measurements of the thermopower whore al low temperatures the relation after [25]

(3)

$$
\alpha \approx \mathrm{T}^{1 / 2}
$$

sems to be obeyed by magretite as well as by Mn-ferrite samples.

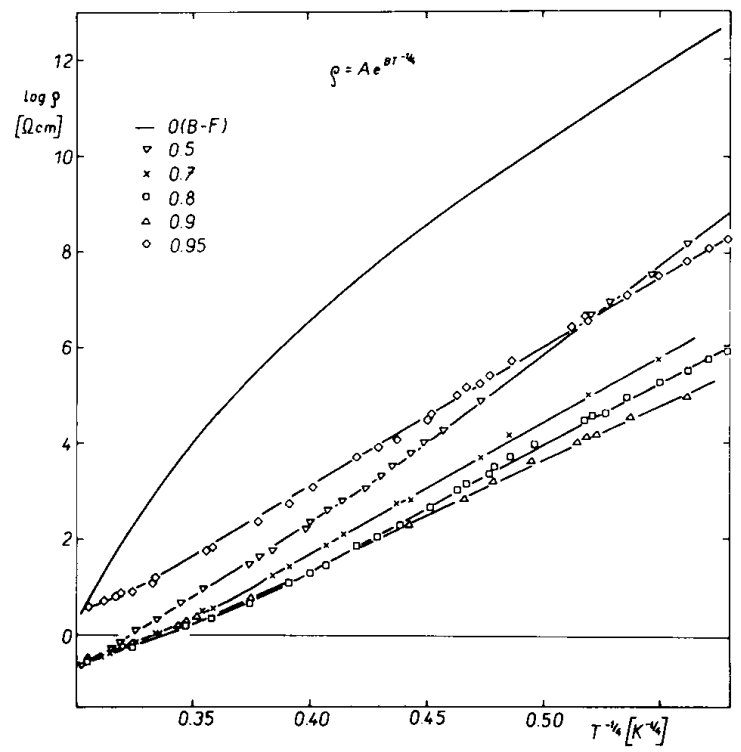

Fig, 8. Demoretration of the Mott's law for magnetites and Mr-ferrites. Symbols indirate the various sample compositions.

At highar temperatures ( T', $40 \mathrm{~K}$ ) the variable ranes hopping yieldine the Mott's law

(4)

$$
\rho=\operatorname{Aexp}\left(\mathrm{B} / \mathrm{T}^{1 / 4}\right)
$$

becomes a more appropriabe deseription in the sase of manganese ferrites as shown on Fig. \&. Ir magretite, however, relation (4) seomo to be satisfactorily obeyed only at low tempexatures ( $\mathrm{T}$ ( $20 \mathrm{~K}$ ) and at

temperatures just below ' ly (of, also [25]). the intermodiate region being the most difficult to interpet Let us recill the complicated behaviour of a for migretit. samples and the ocourerce of maxima in Mn-farriten. "The latter are similar tw maxisno encomterod in fluorine substituted magnetites [18] and nicko] ferrites [19] and nay b. soon as ar evidenoe for the formation of the Coulonb tap in thesta materials (sec disoursin $\Theta . g$. in [5]).

Ilin brizuiour of the electrical conduetivity of magretite above $\mathrm{T} v$ hos

liner suecengfuly explained by the simulancous Wutribution of amall polamon hoppine and small polarmo band rombetion tatidne into arowut short-range ordering offects [20] The bohrviour of manganese firwiter dlowe 100 k. may instead bo inlereselen in lho frame of the ordinary

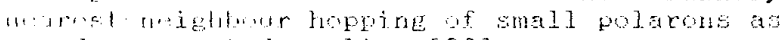

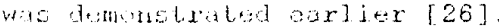


(ara)

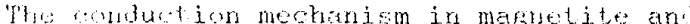
iron $x$ ish nanganes ferrites below rum temperature has a rather complox character. At low temperitures $(\mathrm{T}<40 \mathrm{~K}$ ), a cerrelatod many eloctron hoppirse mechanism of looalized ohare carrics prodominate with high resistivities, low artivation energies and thermopower varying as $7^{1 / 2}$. At higher temperatures $(40 \mathrm{~K} \& \mathrm{~T}<120 \mathrm{~K}$ ) a variable range hopping moranism bocomes important obeying Mott's law and loddre to maxima in the temperature deferderices of the thermopower of manganese forriles. In inagnetite, the thermopower in this particular regior is very sensitive to the specific dopants, to the degrce of ogyxen stoichionetry and to the conditions of host treatmont. At the verwey transition of marctite a jump in electrical properties is caused by the disappearence of the lone-ranee odering of oharge carriera. A certain degrea of a ehort-range ordering above T'v is responsib for the occurence of the ronductivity maximum at about $300 \mathrm{~K}$. The eloctrical proporties of Mr-fexrites above 100 $K$ are aplained by nearost neiehbour small pularon lioping.

\section{Refererces}

11」E.,W Verwoy and F.W. Haayman, "Electronic corductivity and transition point of mas net.ile," Flyssices, vol. 8, pp.979-987, 1941

[a] FA MiLcs, W.B. Weotpha] arit A. von lljpet, "bielectric spentrosopey of ferro Magratio somicordactors", Rev.Mod. Phys., vi. 29, pe $279-307,1967$

[3] B.A. Callour, "Magnetio and electris properlibe of magnetite at low temperatures." Phys. Fev., vol. 94, pp.1577-1585, 1954.

[4] $I$. A. Autin and N.F. Mott, "Polarons in crystalline and non orystalline materials" Ady. Hhys., vol. 18, pp.41-102, 1969.

[5] H.F. Mott, "Hopping conduction and the Coulconle Ex," Festkerperurobleme, vol. 19 pr. $331-361,1979$.

16. H.F. Math, "Materials with nixed valency that show a Verwey transition," Plil. Mag. $v-1$. 34, pp. 327-335, 1980 .

$17]$ S. Ifda, "Structure of $\mathrm{Fe}_{3} \mathrm{O}_{4}$ at low tumperture," phil.Mag., vol. B42, po. 349. 376,1980

(8) J.M. Horis "teotroul traneitions in

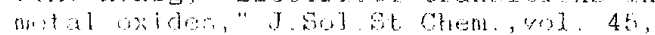
uf $1 \cdots 13,1992$

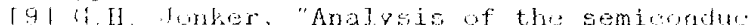
f.ine propliag of whall farritu ] Hhys Chom bolids, vol 9, wo $165-175,1959$

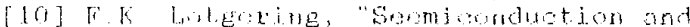

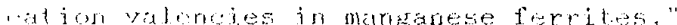

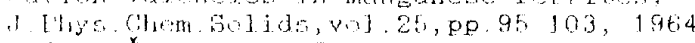

[11\} 2 Sima, "The thernombetrian toromition "f morganese ferrites," Geth. T. Fhys., ?.1 P16, pr 919-929, 1966.

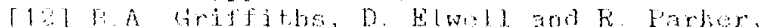

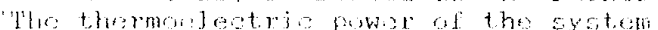
$\mathrm{NiFeO}_{4} \mathrm{FegO}_{4}$, "Fhi\}. Mag., vol 22 . De) $163-174,1970$

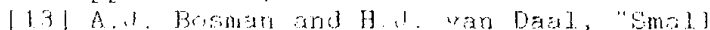

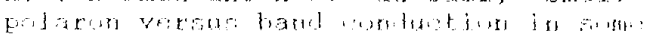

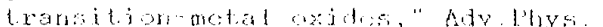
w $19, p, 1+1 \%, 190$

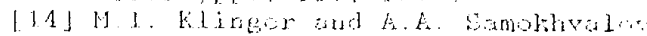

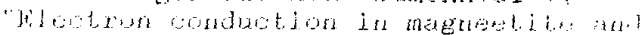

forrites," Fhys.stst.501, , vol, (b) 79 , pp. $9-48,1977$

[15] S. Krupizka, Physik der Ferrite und verwandten magnetischen Oxide. Braunschweig: Vieweg, 1973

[16] A.J.M. Kuipers and V.A.M. Brabers, "Thermoelectric properties of magretite at the Verwey transition," Phys.Rev., vol. B14, pp. 1401-1405, 1976

[17] A.J.M. Kuipers and V.A.M. Brabers, "Electrical transport in magnetite near the Verwey transition, "vol. B20. pp. 594-600, 1979 .

[18] H. Graener, M. Rosenberg, T.E. Whall and M.R.B. Jones, "The low-temperature resistivity and Seebeck coefficient of fluorine-substituted magnetite," Phil.Mag., vol. B40, pp. 389-399, 1979.

[19] T.E. Whal1, K.K. Yeung, Y.G. Proykova and V.A.M. Brabers, "Electrical conductivity and thermoelectric power of nickel ferrous ferrite. Variable range hopping and the Coulomb gap," Phil.Mag., vol. B54, pp. $505-521,1986$

[20] D. Ihle and B. Lorenz, "Small-polaron conduction and short-rangre order in $\mathrm{Fe}_{3} \mathrm{O}_{4}$," J.Phys.C: Sol.State Phys., vol. 19 , pp.5239-5251, 1986.

[21] V.A.M. Brabers, "The preparation of tetragonal single crystals in the $\mathrm{Mn}_{\mathrm{x}} \mathrm{Fe}-\mathrm{x}_{4}$ system," J.Cryst.Growth, vol.8, pp. $26-28,1971$

[22] J.R. Drabble, T.D. Whyte and R.M. Hooper, "Electrical conductivity of magnetite at low temperatures," Solid State Commun., vol. 9, pp. 275-278, 1971 .

[23] 7. Simsa, O. Schreeweiss, "Electrica] conduction of magnetite and some $\mathrm{Mn}$ ferrites at low temporatures," Czech.J. Phys., vo1. B22, pp.1331-1334, 1972

[24] M.L. Knotek and M. Pollak, "Correlation effects in hopping conduction: A treatment in terms of multielectron transitions, "Fhys. Rev. , vol. B9, pp.664-681, 1974.

[25] I.E. Zvyagin, "Or the theory of hopping transport in disordered semiconductors," phys stat. Sol , vol. (b) 58 , pp. 443-449, 1973

[26] Z. Śmsa, J. Śsimšvá and V.A.M. Brabers "Electrical conductivity in maneanese ferrites," in Proceedirgs of the ICFS, Warsaw 1972, vol.2, pp.1294-1299. 